\title{
SAPATHA DALAM RELASI KUASA DAN PENDISIPLINAN PADA MASYARAKAT BALI KUNO ABAD IX-XIV MASEHI
}

\section{THE CURSE IN RELATION TO POWER AND DISCIPLINE IN ANCIENT BALINESE SOCIETY IN THE 9TH TO 14TH CENTURY}

\author{
I Wayan Ardika ${ }^{1}$, I Ketut Setiawan², IGN Tara Wiguna ${ }^{3}$, I Wayan Srijaya ${ }^{4}$ \\ Arkeologi FIB Universitas Udayana \\ ardika52@yahoo.co.id
}

\begin{abstract}
Inscription is a written record which contains regulation or law and should be obeyed by officers or functionaries and community in general. Sapatha or curse was normally written at the end of the inscription which states the punishment for those who objected the regulations or laws. People punished morally if they objected the regulations or law include seven times to be reincarnated and surfering in all their lives. Sapatha or curse was seen as a discourse in relation of power and knowledge of the kings who reigned in the Old Balinese period. This article explores the sapatha or curse in Old Balinese inscriptions dated from the IX up to XIV century. The aim of this article is to describe the relationship of power and knowledge, as well as discipline and punishment in ancient Bali. Data was gained throught documentary studies, and interpreted hermeneutically. Theories of ideology, knowledge and power, as well as discipline and punishment will be applied in this article.
\end{abstract}

Keyword : Sapatha, Relation to Power, Discipline, Ancient Bali.

\begin{abstract}
ABSTRAK
Prasasti adalah sumber tertulis yang memuat ketentuan hukum atau sejenis awig-awig yang harus ditaati oleh semua pihak, baik oleh pejabat kerajaan dan masyarakat yang menerima perintah tersebut. Pada bagian akhir prasasti biasanya dituliskan sapatha atau kutukan yang ditujukan kepada mereka yang berani melanggar aturan-aturan atau ketentuan yang telah ditetapkan oleh raja/penguasa pada masa Bali Kuno. Sapatha atau kutukan merupakan wacana untuk melegitimasi dan mengukuhkan kekuasaan raja atau penguasa pada masa Bali Kuno. Mereka yang melanggar perintah atau ketentuan yang telah ditetapkan oleh raja/penguasa pada masa Bali Kuno akan didenda atau dihukum dengan sanksi moral misalnya: tujuh kali menjelma menjadi mahluk hina seperti cacing ataupun lintah, agar disambar petir, disergap harimau bila sedang berjalan di hutan, hina, papa, dan sengsara selama hidupnya. Artikel ini membahas sapatha atau kutukan yang tersurat dalam prasasti-prasasti Bali Kuno yang terbit pada abad IX-XIV Masehi. Tujuan penulisan ini adalah untuk memahami relasi kuasa dan pendisiplinan yang termuat dalam sapatha dalam kurun waktu lima abad (IX-XIV), ideologi yang melandasi dan makna sapatha atau kutukan. Teori yang digunakan dalam artikel ini adalah teori wacana relasi kuasa (Power and Knowledge), hegemoni, dan teori pendisiplinan dan hukuman (Discipline and punishment ) oleh Michel Foucault. Metode yang digunakan dalam penelitian ini adalah deskriptif kualitatif, yang diawali dengan mencermati dan menganalisis prasasti-prasasti Bali Kuno yang telah diterjemahkan. Mencermati bentuk dan dinamika sapatha yang merefleksikan sistem kepercayaan dan keagamaan masyarakat Bali Kuna.
\end{abstract}

Kata Kunci : Sapatha, Relasi Kuasa, Pendisiplinan, Masa Bali Kuno.

Tanggal Masuk : : 11 Januari 2018

Tanggal Diterima : :09 April 2018 


\section{PENDAHULUAN}

Prasasti berasal dari akar kata Sanskerta praśasti yang artinya piagam atau maklumat (Zoetmulder dan Robson, 1982: II, praśasti). Keterangan tertulis yang tersurat dalam prasasti yang terbit pada abad IX-XIV, merupakan bukti otentik tentang kehidupan politik, sosial, ekonomi, dan budaya masyarakat Bali Kuno. Prasasti memuat berbagai permasalahan yang muncul di masyarakat antara lain: permohonan keringanan pembayaran pajak kepada raja oleh penduduk karena jumlah anggotanya berkurang, manipulasi pajak yang dilakukan oleh para petugas atau pemungut pajak kerajaan, hak dan kewajiban penduduk sebagai pangemong atau pemelihara suatu bangunan suci, permohonan penduduk agar diizinkan oleh raja untuk berhenti memuja sebuah banguan suci karena mereka telah bertugas memelihara bangunan suci lain, permohonan penduduk kepada raja agar diizinkan membeli tanah perburuan milik raja yang terletak di samping desanya karena mereka kekurangan lahan untuk mencari bahan makanan ternak dan kayu bakar.

Raja-raja Bali Kuna senantiasa memikirkan berbagai permasalahan yang dialami oleh rakyatnya. Berbagai pengaduan permasalahan yang disampaikan oleh masyarakat biasanya dibahas dalam persidangan lembaga tinggi kerajaan (pakira-kiran $i$ jro makabehan) yang terdiri atas senapati, nayaka, caksu, dan para brahmana Siwa ataupun Buddha. Raja mempertimbangkan segala masukkan yang diberikan oleh para pejabat tinggi kerajaan untuk memutuskan atau mengabulkan permohonan penduduk. Keputusan raja tersebut ditulis dalam lontar atau lempengan tembaga yang disebut praśasti. Pada bagian akhir praśasti tersebut dimuat sapatha atau sepata (Bahasa Bali kini), yaitu kutukan untuk mengukuhkan keputusan raja agar tidak dilanggar atau diubah oleh siapapun baik di masa kini maupun masa yang akan datang.

Kutukan atau sapatha juga ditemukan dalam prasasti-prasasti tertua di Indonesia (pada masa Sriwijaya) seperti Talang Tuo dan Telaga Batu di Palembang, yang berasal dari abad VII Masehi. Dalam prasasti Talang Tuo yang terbit pada tahun 606 Saka atau 684 Masehi disebutkan bahwa Punta Hyang Sri Jayanaga membuat taman Sri-ksetra untuk kemakmuran rakyat di sekitar Palembang (Talang Tuo). Prasasti itu disertai dengan kutukan terhadap mereka yang tidak tunduk kepada perintah raja. Dalam prasasti Telaga Batu yang juga ditemukan di dekat Palembang, berisi kutukan-kutukan yang seram terhadap mereka yang melakukan tindakan kejahatan dan tidak tunduk kepada perintah raja, namun prasasti ini tidak berangka tahun ( Casparis, 1956: 15-29; Kartodirdjo dkk. 1977:52-53).

Prasasti-prasasti Jawa Kuna terutama yang terkait dengan upacara penetapan śima lazim memuat sapatha atau kutukan. Sima adalah perdikan atau daerah yang bebas dari pajak, karena raja/penguasa berkepentingan untuk tujuan tertentu atas tanah atau wilayah tersebut (Schrieke, 1919: 128-130: 1975: 11-14; Vollenhoven, 1931: 164).

Prasasti Kembangarum yang berangka tahun 824 Saka atau 907 Masehi menjelaskan Rakryan di Wantil Pu Pảlaka penduduk Desa Wulakan beserta istrinya yakni Dyah Prasảda dan ketiga putranya yaitu $\mathrm{Pu}$ Palaku, Pu Gowinda, dan $\mathrm{Pu}$ 
Wańi menetapkan Desa Pańgumulan watak Puluwatu sebagai śima atau perdikan Bhatara dan Bhatari di Kinawuhan. Pejabat yang hadir pada saat itu antara lain Rakryan Mapatih I Hino Pu Dakșa Sań Bảhubajrapratipakșakșaya (Bosch, 1925, OV:41). Desa Pańgumulan yang berstatus sebagai sima ditetapkan bebas pajak sehingga tidak boleh dimasuki oleh petugas pemungut pajak dan pejabat sejenisnya. Pada bagian akhir prasasti tersebut terdapat kutukan sebagai berikut: Illb.6

...yapuan yan ana wuań ñanyaya a sing umulah iki sima wanua pañgulmulan watak puluwatu ńuniwaih yan puputtaya kadi lawas sań hyań candrảditya hana riń nảkasa sumuluh hin andabhuwana mañkana lawasnya pańguhań 8. pańcamahảpảtaka...(Bosh, 1925: OV, 45).

Terjemahannya sebagai berikut: apabila ada orang yang mengubah ketentuan daerah perdikan desa Panggumulan wilayah Puluwatu hukumlah yang bersangkutan selama bulan dan matahari menyinari dunia, selama itu pula lima bencana besar yang dideritanya.

Kutukan serupa juga ditemukan dalam Prasasti Baru, yang terbit pada tahun 952, Saka atau 1030 Masehi pada masa pemerinahan raja Erlangga. Prasasti ini berkaitan dengan penetapan Desa Baru sebagai śima. Raja Erlangga pernah menginap di Desa Baru, dan beliau berjanji pada malam hari untuk kelak menetapkan desa tersebut berstatus sima, seandainya baginda dapat mengalahkan musuhnya di Hasin. Setelah raja Erlangga berhasil mengalahkan musuhnya di Hasin, beliau memenuhi janjinya dengan menetapkan Desa Baru berstatus sima. Pada bagian akhir prasasti Baru ditulis sapatha sebagai berikut: 39.

/l yảpwan hana sira wwang durảcảra tan yatnả $i$ sarasa nikến̉ śỉmả ńkẽ ring baru kabwa-/t karmaknanya salwirning pancamahảpảta ka,..

(Brandes, 1913: 134).

Terjemahannya sebagai berikut: apabila ada orang jahat, yang tidak hati-hati dan mengindahkan segala ketentuan tentang daerah perdikan di desa Baru agar perbuatannya itu menyebabkan lima jenis bahaya besar yang dideritanya.

Lima jenis bahaya besar atau kejahatan (pancamahảpảta) yang dimaksud adalah membunuh seorang brahmana, minum minuman yang memabukkan, mencuri, berzina terhadap istri guru, dan kejahatan berat (Zoetmulder dan Robson, 1982: II, mahậpậtaka , pańcamahậpậtaka).

I Wayan Ardika (2013:10) menyatakan bahwa raja-raja Bali Kuno menetapkan berbagai ketentuan hukum Hindu yang terkait dengan warisan, perkawinan, kepemilikan tanah, utang-piutang, jual-beli, parusya (memfitnah, memaki-maki, memukul, menikam), tatayi (meracun, menenung), astacorah (mencuri), sahasa (memaksa) dan pungutan untuk kelompok profesional yang ada di masyarakat pada masa itu. Elemenelemen hukum Hindu yang berlaku pada masa Bali kuno tidak jauh 
berbeda dengan ketentuan yang diterapkan pada masa Majapahit (Mulyana, 1967: 102, 116, 122, 130). Dengan kata lain bahwa raja-raja Bali Kuno pada abad IX-XIV telah menerapkan hukum Hindu seperti yang dipraktikkan pada masa Majapahit untuk memperkuat kedudukan mereka.

Sistem norma dan perundang-undangan serta denda dibahas dalam penelitian "Bali antara abad VIII-XIV: Upaya Rekonstruksi Sejarah Bali Kuno berdasarkan Tinggalan Arkeologi" (Ardika dan Setiawan, 2012: 80-88). Dalam penelitian tersebut dibahas mengenai sistem norma dan perundang-undangan dalam masyarakat Bali Kuno pada abad VIII-XIV. Kitab perundang-undangan yang disebutkan dalam prasasti Bali Kuno antara lain: Uttara Widdhi Balawan, Raja Wacana atau Raja niti, Agama, Manawakamandaka, Dasa Sila, Smerti dan Pancasisksa. Kitab-kitab Hindu tersebut digunakan sebagai acuan atau sumber hukum oleh raja-raja Bali Kuno (Ardika dan Setiawan, 2012: 84). Berbagai sanksi dan denda juga diberlakukan terhadap masyarakat Bali Kuno seperti astadusta (delapan kejahatan), wakcapala (salah ucap/caci-maki), hastacapala (kesalahan dengan tangan), anampyal (memukul), dan anuding (menuding atau menunjuk-nujuk dengan jari telunjuk ?) wajib dikenai denda (Ardika dan Beratha, 1996: 27; Ardika dan Setiawan, 2012: 88). Sanksi moral berupa kutukan juga disinggung dalam penelitian tersebut, namun tidak dibahas secara tuntas.

$$
\text { Ketentuan mengenai }
$$

warisan, perkawinan, kepemilikan tanah, utang-piutang, dan jual-beli juga telah diatur dalam prasastiprasasti Bali Kuno. Tindakan kekerasan dengan tangan, kaki, dan kata-kata (mulut) yang tergolong parusya dibahas dalam penelitian tersebut. Selain itu meracun (tatayi) dan menenung (aneluh) juga dibahas dalam penelitian itu (Setiawan dan Ardika, 2013: 235240).

Prasasti dapat dikatakan sebagai wacana yang merupakan rangkaian ketentuan atau aturan yang dapat dijadikan acuan oleh masyarakat pada masa Bali Kuno. Dalam pemikiran Barker (2014) wacana adalah tindakan atau katakata yang menyatukan bahasa dan praktik yang merujuk pada sejumlah cara dengan aturan-aturan tertentu tentang subjek untuk memperoleh makna (Barker 2014: 79). Produksi pengetahuan lewat bahasa memberikan makna pada objek material dan praktik sosial yang disebut sebagai praktik diskursif. Pembentukan wacana sendiri terjadi lewat keberulangan motif atau gugus ide, praktik-praktik, dan bentukbentuk pengetahuan yang meliputi sejumlah arena kegiatan manusia. Prasasti seperti yang telah dikemukakan di atas adalah titah atau perintah raja/penguasa untuk tujuan tertentu, berisi aturan tentang praktik sosial, penetapannya yang disaksikan oleh sejumlah pejabat tinggi kerajaan, pejabat yang menerima anugerah raja/penguasa, dan sapatha atau kutukan terhadap mereka yang melanggar ketentuan yang telah ditetapkan.

Sapatha atau kutukan dalam prasasti-prasasti Bali Kuno yang berasal dari abad IX-XIV bentuknya berbeda seiring perkembangan waktu. Kutukan yang dimuat dalam prasasti-prasasti dari abad IX cenderung lebih pendek dibandingkan dengan prasasti yang terbit pada periode berikutnya. Bentuk-bentuk kutukan merupakan 
salah satu fenomena yang menjadi permasalahan untuk dikaji dalam tulisan ini.

kuasa

Fungsi kutukan dalam relasi kekuasaan/kekuatan (power) seorang raja. Selama kurun waktu lima abad akan dapat diidentifikasi kekuasaan raja-raja pada masa Bali Kuno. Mengacu pada pemikiran Michel Foucault $(1977 ; 2002)$ bahwa pendisiplinan, ketaatan, kejujuran, dan etika moral, dapat dikaitkan dengan makna kutukan sebagai cara atau media pendisiplinan.

Kutukan atau sapatha yang dimuat pada bagian akhir prasasti mencerminkan relasi kuasa seorang raja/penguasa dan masyarakat atau rakyat. Masyarakat harus mentaati ketentuan yang termuat dalam kutukan. Dengan kata lain, kekuasaan (power) seorang raja/penguasa akan mantap bila rakyatnya berpartisipasi, taat dan patuh terhadap ketentuan yang berlaku.

\section{METODE}

Studi ini bertujuan untuk memahami bentuk, fungsi dan makna kutukan pada masa Bali Kuno. Penelitian ini menggunakan pendekatan kualitatif interpretatif. Pengumpulan data dilakukan melalui studi kepustakaan yakni mencermati isi atau ketentuan yang termuat dalam 200 prasasti dari masa Bali Kuno yang terbit antara abad IX-XIV Masehi. Prasasti-prasasti yang memuat sapatha atau kutukan dipilih sacara purposif yang mewakili masing-masing periode atau zaman selama kurun waktu lima abad, yaitu abad IX-XIV.

Data kepustakaan yang relevan dengan penelitian ini diharapkan dapat melengkapi data primer yang berhasil dikumpulkan melalui kajian terhadap prasastiprasasti Bali Kuno. Ketentuan sapatha yang tersurat dalam prasasti Bali diinterpretasikan secara hermeneutik. Hermeneutika adalah metode pemahaman makna melalui penafsiran (Hoed, 2008: 83). Hermenutika berarti memahami suatu teks tidak hanya berdasarkan kata-kata yang ada di dalamnya, tetapi pada keseluruhan teks sebagai hasil karya.

\section{HASIL PENELITIAN}

Ideologi adalah sekumpulan gagasan yang menjadi panduan bagi kelompok manusia dalam bertingkah laku untuk mencapai tujuan tertentu (Takwin. 2003: 7). Lebih lanjut para ahli menyatakan bahwa ideologi dan kepentingan sangat menentukan pikiran, sikap, dan tindakan manusia (Thompson, 2007: 16-20, 47; Althusser, 2008: 34, 39).

Barker (2003: 137-140) menguraikan pendapat beberapa para ahli tentang ideologi. Menurut Karl Marx ide-ide dominan dalam masyarakat apapun adalah ide-ide dari kelas berkuasa. Selain itu, ia juga mengingatkan bahwa hal yang dianggap karakter sejati dari relasirelasi sosial dalam kapitalisme pada kenyataannya adalah mistifikasi pasar. Lebih lanjut, menurut Gramsci ideologi adalah ide-ide, gugus makna, dan praktik yang mendukung kekuasaan kelas sosial tertentu, meskipun diklaim sebagai dalil-dalil kebenaran yang berlaku universal. Ideologi dimengerti sebagai pengalaman yang dihayati maupun seperangkat ide-ide sistematis yang berperan mengorganisasi dan mengikat blok antarunsur sosial yang beraneka ragam. Michel Foucault menyatakan bahwa konsep ideologi pada dasarnya dalam relasirelasi kekuasaan dan pengetahuan. 
Ideologi bisa dipahami sebagai upaya untuk menetapkan makna (to fix meaning) demi tujuan yang spesifik.

Ideologi yang tersirat dalam kutukan atau sapatha yang tertulis dalam prasasti seperti yang dicontohkan di depan adalah penguatan aturan dan ketentuan yang ditetapkan oleh raja/penguasa agar tetap tegak dan tidak diubah oleh siapapun kini maupun di masa yang akan datang. Mereka yang berani melanggar atau mengubah ketentuan yang ditetapkan oleh raja dan disaksikan oleh pejabat tinggi kerajaan, para dewa, daitya, mahluk halus, dan seluruh arah mata angin agar tujuh kali menjelma, menjadi mahluk hina seperti cacing, lintah dan senantiasa sengsara dan menderita selama hidupnya.

Para saksi yang disebutkan dalam kutukan itu terdiri atas pejabat tinggi kerajaan termasuk para pendeta Siwa dan Buddha, serta para dewa, daitya, dan mahluk halus lainnya. Dengan kata lain, para saksi yang diminta untuk mengukuhkan perintah raja/penguasa tersebut bersifat skala dan niskala. Mengikuti pendapat Lanur (Atmadja, dalam Ardika (ed). 2016: 21) bahwa hakikat manusia itu adalah bersifat jasmani dan rohani Tubuh dan roh manusia adalah satu kesatuan. Sehubungan dengan itu, maka untuk melanggengkan perintah raja/penguasa ditampilkan saksi skala (jasmani) dan niskala (rohani). Selain itu, manusia sebagai Homo religious adalah mahluk yang meyakini bahwa di luar dirinya ada kekuatan adikodrati, agama-agama dunia menyebutnya Tuhan. Tuhan memberikan manusia ajaran agama sebagai resep bertindak dalam menata suatu kehidupan yang damai baik di alam ini (fana) maupun di alam baka (Atmadja, dalam Ardika (ed). 2016: 29). Penyebutan saksi para dewa dan mahluk halus dalam kutukan dimaksudkan untuk menguatkan dan melanggengkan perintah raja/penguasa agar dipatuhi oleh masyarakat.

Kepatuhan atau ketaatan terhadap titah raja/penguasa dapat diinterprertasikan sebagai upaya untuk melanggengkan kekuasaan. Kekuasaan adalah kemampuan untuk memengaruhi, mengatur pikiran atau kehendak dan tingkah laku orang lain. Manifestasi dari kekuasaan itu adalah perintah, aturan, dan hukum. Penguasa adalah pencipta serta penegak hukum serta pengatur ketertiban di tengah masyarakat (Lubis, 2014: 182). Prasasti yang diterbitkan oleh raja-raja Bali Kuno dapat dikatakan sebagai sumber hukum yang mengatur dan mengontrol tingkah laku dan ketertiban masyarakat.

\section{Bentuk dan Dinamika Kutukan (Śapatha) Pada Masa Bali Kuno}

Kutukan yang tersurat dalam prasasti-prasasti Bali Kuno menunjukkan dinamika atau mengalami perubahan dari yang pendek menjadi lebih panjang seiring dengan perubahan waktu. Berikut diberikan contoh-contoh sapatha pada prasasti-prasasti Bali Kuno dari periode ke periode berikutnya.

Prasasti 003. Trunyan Al yang berangka tahun 833 Saka terdapat sapatha sebagai berikut: IVa.2.

“...tani sanggurugyan ya
kabudi kabudi, marang
sumuranggurugi ya sapan ulih
bhatàra...." (Goris, 1954)

Terjemahannya sebagai berikut: IVa.2.

“.....tidak boleh melanggarnya (keputusan raja) sampai 
dikemudian hari. Barang siapa yang melanggarnya dikutuk oleh bhatara....." (Ardika dan Beratha, 1996: 57).

Penerbitan prasasti ini

bertujuan untuk menguatkan

perintah raja/penguasa kepada

penduduk Desa Trunyan berupa

pembebasan sejumlah pajak, karena

mereka ditugaskan mendirikan dan

memelihara bangunan suci untuk

Bhatara Da Tonta di desanya.

Sapatha yang hampir sama juga tertulis dalam prasasti Prasasti Trunyan $B$ yang berangka tahun 833 Saka. Prasasti ini bertujaun untuk menguatkan perintah raja tentang pembebasan pajak kepada penduduk Desa Trunyan karena mereka ditugaskan memelihara bangunan suci untuk Bhatara $\mathrm{Da}$ Tonta di desanya. Selain itu, penerbitan prasasti ini dimaksudkan untuk menegaskan keputusan raja/penguasa tentang pungutanpungutan yang diwajibkan kepada penduduk Desa Air Hawang (Abang), terutama pada waktu penyelenggaraan upacara untuk Bhatara Da Tonta. Kutukan pada prasasti Prasasti Trunyan B adalah sebagai berikut:

IIIb.1.

“.....kunang yathaña ta- 2. ni kasanggurugyanna kabudikabudi to thaninda bhapàra di turunan anggan luk pirumahin gat to banua do air rawang, yan ada manunggurugi ya, sapan ulih 3. bhatàra, ping pitu ya mangjanma tani kapadan min uraña janma pàpasangsara

sadàkàla.....(Goris, 1954: 59 ).

Terjemahannya sebagai berikut: IIIb.1.

“....Demikianlah agar
(keputusan raja) tidak 2.
diubah/diganggu sampai di

kemudian hari yang merupakan wilayah Bhatara di Turunan sampai di tikungan perbatasan desa Air Rawang. Apabila ada yang melanggarnya dikutuk oleh 3 . bhatara, tujuh kali ia menjelma tidak akan menyerupai manusia, selalu derita nestapa akan menimpanya....." (Calenfels, 1926:24; Goris, 1954: 59; Ardika dan Beratha, 1996: 63).

Dalam Prasasti Bedulu yang berangka tahun 890 Saka atau 968 Masehi, dan diterbitkan atas nama Sri Haji Tabanendra Warmmadewa oleh pejabat $\mathrm{Da}$ Kumpi Daradyah Kabilyan. Tujuan penulisan prasasti ini untuk menguatkan keputusan seorang pejabat kerajaan berupa pembebasan beberapa pajak dan kewajiban lainnya kepada penduduk Desa Langanan, karena penduduk berkewajiban memelihara bangunan suci untuk pemujaan Bhatara Hyang Api. Kutukan/ sapatha dalam prasasti tertulis sebagai berikut: Ilb.6.

“.....yathana tani kawukilwukilen dlaha ning dlaha, asing manuruktaya, tani temwan sarba upayana, kopadrawan ya...." (Wiguna, 1981: 67)

Terjemahannya sebagai berikut: Ilb.6.

“....(keputusan raja) agar
tidak dilanggar sampai di
kemudian hari, barang siapa
yang mengubah/melanggar
keputusan ini, tidak berhasil
segala usahanya, terkena
bencanalah ia...." (Wiguna,
1981: 67).

Berdasarkan ketiga teks prasasti tersebut dapat diketahui bahwa mereka yang melanggar ketentuan yang ditetapkan oleh 
raja/penguasa agar dikutuk oleh bhatara atau manifestasi Tuhan dan tujuh kali menjelma, serta senantiasa menderita. Ketiga teks sapatha tersebut berasal dari awal abad ke-10 Masehi.

Berikut kutipan prasasti yang berasal dari masa pemerintahan Raja Udayana Warmadewa yakni Prasasti Batur Pura Abang A yang berangka tahun 933 Saka atau 1011 Masehi. Prasasti ini berisi tentang keputusan raja terkait dengan pembebasan pajak kepada penduduk Desa Air Hawang (Abang) karena jumlahnya berkurang. Adapun sapatha atau kutukannya sebagai berikut:

Xa.2.

“.....kunang asing mukil-mukil ya tan têmwang sarbwa upa3. yana, mwang phalanya tke putunya, the buyut buyut ya kawuri, kunang asing umambahambaá ya atmahan taktak, wdit, lintaá, salwir ning sarbwa papà, mahàpataka 4. tmunya....." (Goris, 1954: 94).

Terjemahannya sebagai berikut:

Xa.2.

“.....barang siapa yang berani melanggar/merusak agar tidak berhasil segala 3 . usahanya, serta hasil perbuatannya sampai ke cucunya, selanjutnya sampai ke cicit (buyut) nya kelak, selanjutnya barang siapa yang melanggarnya. (agar) menjelma menjadi cecak, ulat, lintah, segala jenis kesengsaraan, penderitaan/bencana yang amat dahsyat 4. akan ditemuinya......" (Ardika dan

Beratha, 1998: 60).

Dalam prasasti Dawan yang terbitkan oleh Raja Anak Wungsu pada tahun Saka 975 atau 1035 Masehi tentang anugerah sebidang tanah dan 30 ekor kerbau kepada Desa Lutungan, karena mereka memelihara bangunan suci Antakunjarapada. Kutukan yang tersurat dalam prasasti tersebut adalah sebagai berikut:

IX.a.

1. ".....wineh saphala tungtung satya, tinadah ri bhatara punta hyang, maka pamursita masi-

2. nghala bentuk tunggal bharanya ma 4 tanda haji. panadah úapatha rasa nikang satya, indah ta bhapàra punta hyang, hyang agasti mahàåsi, purwwa, dakșina, paḉcimottara, madya urdhamadaá, rawi, șaḉi, kși-

3. ti jala pawana, hutàsana, ahoratri sandyadwaya, yakśa, ràkśasa, pisàca, pretàsurà garuda gandarwa, kinara mahoràga, catwari lokapàla, yama baruna, kuwera besawa mwang putrade-

4. watà, pañcakusika, nandišwara, mahàkàla, sadwinàyaka, durgadewi, caturastra, ananta surendra ananta kala måtyu, gana bhuta raja bhuta, kita milu masarira, masuking sarba masarira saka-

5. la saksi bhuta, tumon angadoh lawan aparê, rahina wngi, at ångö ikang samaya sapatha sumpah pamangmang mami ri kita 
hyang kabeh, yàwat tikang wwang duràcàra tan yatna ryyanugraha padu-

6. ka haji irikang karaman $i$ lutungan sapasuk thàni, brahmana, ksatrya wesya sudra, hadyan hulun rareyatuha lanang wadwan grahasta wiku, nayaka caksu parasandhiwiûa asi-

IX.b.

1. ng umulahulah anugraha pàduka haji, dlàhaning dlàha tasmat kabwataknanya patyananta ya kamung hyang, de yan tat patiya tan panonliha ri wuntat, tan tinghala hiringan tarung $i-$

2. ng adgan, tutuh tundunya belah kapalanya, sbitakenwtangnya, wetwaken dalmanya, dudut hatinya pangan dagingnya, inum rahnya wehi prarantika, yan para ring alas sahut ning ula, puliraknaning

3. dewa manyu, yan para ya ring tgal sambêring glap, sarba roga rumancaya arah ta kita hyang kusika garga metri kurusya, patanjala, suwuk lor kidul kulwan wetan bwangaken ring a-

4. kasa, salembitaken sanghyang kabeh tibanikang samudra klmakni dawuhan duduting tuwiran, sanghapning wahaya, mulih ring naraka loka, palun de sang yama kingkara bala, ping pitu mang-

5. janma papasangsara, sajiwakala saliring duhka bhuktinya, sakeliking janma têmahanya, awuka tan tmung sama,

mangkana tmahanikang

umunarukta

wwang

prasasti kmitanikang karà-

6. man i lutungan sapasuk thani, tlas sinaksyan $i$ (Santosa, 1965: 21-36)...."

Terjemahannya sebagai berikut:

IX.a.

1. "Diberikan hasil janji terpenting (dari raja), selanjutnya dimohonkan kepada Bhatara Punta Hyang, sebagai penghormatan dipersembahkan

2. emas tanda kerajaan..... dimohonkan kutukan, isi kutukan: Wahai paduka Bhatara Dapunta Hyang, Hyang Agasti, Maharsi, timur, selatan, barat, utara, tengah, atas, bawah, matahari, bulan

3. bumi. air, angin, api, siang malam, pagi sore, yaksa, raksasa, pisaca, pretasura, garuda, gandharwa, kinara, mahoraga, catur lokapala : Yama, Baruna, Kuwera, Basawa, dan Putradewata,

4. Pancakusika, Nindiswara, Mahakala, Sadwinayaka, Durgadewi, caturasra : Ananta Surendra, Ananta Kalamrtyu, Gana Bhuta, dan Raja Bhura, engkaulah yang ikut menjelma, menyusupi semua makhluk. Engkaulah yang ikut

5. yang menjadi saksi bhuta yang nyata, dapat melihat yang jauh maupun yang dekat, (juga) pada siang dan malam. Dengarkanlah janji kutukan sumpah kami kepadamu Hyang semua. Jika 
ada orang yang jahat, tidak mengindahkan anugerah paduka

6. raja kepada penduduk Desa Lutungan sewilayahnya, brahmana, ksatrya, wesya dan sudra, para budak, tua-muda, laki-perempuan, grahasta, wiku, nayaka, caksu, parasandhiwisa

IX.b.

1. yang merusak/melanggar anugerah paduka raja, sampai kelak kemudian hari, semoga ia mendapat beban yang sangat berat (dalam hidupnya), bunuhlah dia, wahai yang mulia Hyang, jika ia tidak mati, supaya tidak selamat sampai kemudian hari, dan tidak dapat melihat siapapun, terjanglah

2. badannya, pukul punggungnya, belah kepalanya, sobek perutnya (dan) keluarkan jeroannya, tarik hatinya, makan dagingnya minum darahnya, akhiri jiwanya. Jika ia pergi ke hutan supaya dipagut oleh ular, diputar/dibingungkan oleh

3. Dewa Manyu, jika pergi ke ladang supaya disambar petir, supaya semua duka nestapa dideritanya. Wahai Engkau Hyang Kusika, Garga, Metri, Kurusya, Patanjala, terjanglah dari selatan, utara, barat dan timur, lemparkanlah ke

4. angkasa, agar disiksa oleh para dewa, campakanlah ke samudra, tenggelamkan di danau, ditarik oleh tuwiran (sejenis binatang laut yang buas), agar disambar oleh buaya, kembalikan ke neraka, dipukul oleh Sang Yama, pasukan Sang Kingkara, tujuh kali men-

5. jelma papa-nestapa seumur hidup, sedih/duka yang berkepanjangan yang dirasakannya, segala penderitaan manusia dialaminya, binasa tidak seperti manusia pada umumnya. Demikianlah akibat dari orang yang melanggar (isi) prasasti yang dijaga oleh penduduk

6 sewilayahnya. Telah disaksikan oleh (:para pejabat kerajaan)......"

(Santosa, 1965: 34; Ardika dan Beratha. 1998: 167-171).

Berdasarkan kutipan dan paparan di depan ternyata bahwa kutukan atau sapatha yang tersurat dalam prasasti-prasasti Bali Kuno menunjukkan perubahan atau dinamika dari masa ke masa. Kutukan yang tertulis dalam prasasti Trunyan dari abad IX misalnya jauh lebih pendek dibandingkan dengan prasasti Dawan yang berasal dari abad XI. Para saksi yang diseru yakni dewa, daitya, arah mata angin dan mahluk halus jumlahnya semakin banyak untuk menghukum mereka yang melanggar ketentuan yang ditetapkan oleh raja/penguasa dari periode ke periode berikutnya. Fenomena ini tampaknya mencerminkan ideologi, relasi kuasa dan pengetahuan yang dipahami oleh raja/penguasa mengalami perubahan dari masa ke masa berikutnya. 


\section{DISKUSI DAN PEMBAHASAN}

Kuasa/pengetahuan

pertama-tama bekerja melalui bahasa. Anak-anak pada tingkat pertama belajar bicara atau bahasa, ia menerima pengetahuan dasar serta aturan-aturan kebudayaan pada saat yang sama. Menurut Foucault kuasa tidak selalu bekerja melalui penindasan dan represi, tetapi melalui normalisasi dan regulasi. Normalisasi berarti menyesuaikan diri dengan normanorma, membuat norma-norma, sedangkan regulasi berarti menyesuaikan diri dengan aturanaturan (Lubis, 2014: 177-179).

Prasasti adalah sumber tertulis yang memuat kehendak atau keinginan raja/penguasa, selanjutnya dituliskan pada daun lontar, lempengan tembaga, emas, dan/atau batu. Keinginan raja/penguasa disertai dengan aturan-aturan, norma, dan sanksi terhadap mereka yang melanggarnya. Sapatha dalam hal ini dapat dianggap sebagai sanksi moral (imaterial) terhadap mereka yang berani melanggarnya. Dalam konteks ini prasasti termasuk sapatha adalah produk aturan dan hukum yang diciptakan oleh raja/penguasa, dan sekaligus merepresentasikan kekuasaan. Raja-raja Bali Kuno telah menciptakan strategi atau sistem pengawasan dimana setiap individu membawa pengawasan tersebut ke dalam dirinya sehingga membuat mereka menjadi pengawas dirinya sendiri. Setiap individu melakukan pengawasan tersebut dalam melawan dirinya sendiri. Menurut Foucault (2002: 192-193) fenomena itu merupakan rumusan yang hebat, dimana kekuasaan tetap terus dijalankan, namun biayanya dapat ditekan seminimal mungkin. Sanski dengan kutukan merupakan perubahan dari hukuman jasmani ke hukuman jiwa atau kemauan (Ritzer dan Goodman, 2012: 618-619; Setiawan dan Ardika, 2013:224).

Seperti dicontohkan bahwa kutukan atau sapatha yang tersurat dalam prasasti-prasasti yang lebih muda cenderung lebih panjang dibandingkan dengan yang lebih tua/kuno. Fenomena itu mungkin terkait dengan pengetahuan tentang agama dan hukum Hindu yang dipahami oleh raja/penguasa pada masa Bali Kuno semakin meningkat. $\mathrm{Hal}$ ini menunjukkan adanya hubungan antara kekuasaan dengan pengetahuan.

Kutukan yang tersurat dalam prasasti Trunyan Al dan B misalnya hanya menyebutkan permohonan kepada bhatara atau dewa, namun tidak disebutkan secara rinci atau jelas dewa yang dimaksud. Dalam prasasti Dawan yang berangka tahun 975 Saka atau 1053 Masehi disebutkan permohonan kepada Maharsi Agastya, ke empat arah mata angin, tengah, atas dan bawah, siang dan malam, mahluk halus, Dewa Catur Lokapala, Dewa Yama, Baruna, Kuwera, dan Besawa (Indra), dan dewa-dewa lainnya. Pengetahuan tentang filosofi dan sistem perdewaan dalam agama Hindu yang dipahami oleh Raja Anak Wungsu yang menerbitkan prasasti Dawan tampaknya jauh lebih lengkap atau komprehensif dibandingkan dengan penguasa yang menerbitkan prasasti Trunyan. Fenomena ini merepresentasikan relasi kuasa dan pengetahuan (power and knowledge).

Dalam prasasti Sawan C atau Blantih $\mathrm{C}$ yang terbit pada tahun 1020 Saka atau 1098 Masehi atas nama Raja Sakalendukirana terdapat ungkapan sebagai berikut: Illb. 
...lawan tan kapasukkana deninguttarawiddhi balawan (Brandes, 1885: 615-619; Ardika dan Sutjiati Beratha, 1998: 416).

Terjemahannya sebagai berikut:

agar tidak dimasukkan (ketentuan pajak) sesuai dengan rincian dalam kitab Uttara Widdhi Balawan (Setiawan dan Ardika, 2013: 219).

Fenomena yang mirip juga ditemukan dalam prasasti Buwahan D, yang berangka tahun Saka 1103 atau 1181 Masehi, dan terbit pada masa pemerintahan Raja Jayapangus disebutkan kitab Manawakamandaka. Ungkapan dalam prasasti itu sebagai berikut: Ila.2.

...paduka çri maharaja 3.
rumengổ
manawakamandaka,...
(Suhadi, 1979: 40).

Terjemahannya sebagai berikut:

$$
\begin{aligned}
& \text { Paduka Sri Maharaja } \\
& \text { (Jayapangus) mendengar isi } \\
& \text { kitab Manawakamnadaka. }
\end{aligned}
$$$$
\text { Kitab Manawakamnadaka }
$$

juga ditulis dalam prasasti Tumbu yang berangka tahun 1247 Saka atau 1325 Masehi, yang berasal dari masa pemerintahan Raja Sri Bhatara Mahaguru (Suhadi, 1979: 183; Setiawan dan Ardika, 2013: 220).

$$
\text { Berdasarkan kutipan }
$$
prasasti-prasasti tersebut di atas, raja-raja Bali Kuno yang memerintah pada abad XI-XIV telah mendengar atau memahami isi kitab Uttara Widdhi Balawan dan Manawakamnadaka yang merupakan sumber hukum Hindu. Dengan kata lain, kitab hukum Hindu tersebut tampaknya telah dipraktikan dalam kehidupan masyarakat pada masa Bali Kuno. Pengetahuan (knowledge) raja-raja Bali Kuno tentang hukum Hindu sekaligus dipakai acuan untuk mengontrol dan mengatur masyarakat agar mereka patuh dan mengakui kekuasaan sang raja. Hal ini mengindikasikan adanya relasi kuasa dan pengetahuan raja-raja Bali Kuno (Foucault, 2002: 66). Selain memahami hukum Hindu, raja-raja Bali Kuno menyebut dirinya titisan dewa di dunia yang bertugas menyejahterakan rakyatnya. Raja Anak Wungsu misalnya, dalam prasasti Dawan yang berangka tahun 975 Saka atau 1053 Masehi disebutkan bahwa raja diibaratkan sebagai perwujudan Dewa Hari (Wisnu). Teks dalam prasasti bunyinya sebagai berikut:

karunatma saksat niran hari murti, nityasa nira kumingking sakaparipurnakna rat rinaksanira,.( Ardika dan Beratha, 1998: 138)

Terjemahannya sebagai berikut:

belas kasihan (Raja Anak Wungsu) terhadap jiwa (rakyat) bagaikan Dewa Hari (Wisnu) yang selalu memikirkan kesempurnaan atau kesejahteraan dunia yang dikuasainya (Atmodjo, 1972: 23-25; Ardika dan Beratha, 1998: 138).

Metafora yang hampir sama juga ditemukan dalam prasasti Sembiran $C$ yang berangka tahun 1103 Saka atau 1181 Masehi, dan terbit atas nama Raja Jayapangus. Teks dalam prasasti tersebut sebagai berikut: lla.3. 


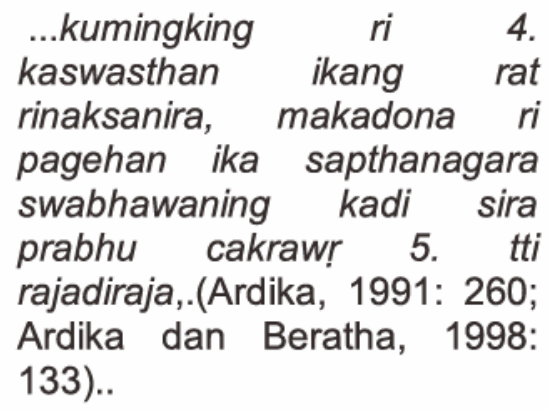

Terjemahannya sebagai berikut:

\begin{tabular}{|c|}
\hline $\begin{array}{lr}\text { (Raja } & \text { Jayapangus) } \\
\text { memikirkan } & \text { tentang } \\
\text { kesejahteraan dunia/kerajaan } \\
\text { yang beliau jaga/kuasai, untuk } \\
\text { tujuan tegaknya Saptanegara } \\
\text { (tujuh negara), perilaku beliau } \\
\text { sebagai seorang prabhu atau } \\
\text { penguasa tertinggi dunia atau } \\
\text { raja di raja (Ardika dan Sutjiati } \\
\text { Beratha, 1998: 133; Ardika }\end{array}$ \\
\hline
\end{tabular}

Berdasarkan kutipan

tersebut, Raja Jayapangus mengklaim dirinya sebagai raja atau penguasa tertinggi (raja di raja), yang senantiasa memikirkan kesejahteraan dunia/kerajaan yang dipimpinnya, demi tegaknya Saptanegara (tujuh negara). Menurut Paul Ricoeur (Lubis 2014: 170) bahwa metafora memiliki makna yang sangat dalam. Raja Anak Wungsu yang menyebut dirinya sebagai titisan Dewa Wisnu. Raja Jayapangus mengkliam dirinya sebagai penguasa dunia dan raja di raja dapat dimaknai sebagai penguasa tertinggi yang sangat kuat dan berpengaruh.

Pernyataan yang ditulis dalam prasasti-prasasti tersebut di depan mengindikasikan pengetahuan raja-raja Bali Kuno tentang filsafat dan hukum Hindu. Pengetahuan tersebut digunakan untuk mengontrol, mengikat, dan mendisiplinkan kehidupan masyarakat.
Kutukan atau sapatha yang dicantumkan pada bagian akhir prasasti berlaku untuk semua golongan (brahmana, ksatriya, wesya, dan sudra) dalam masyarakat. Dalam prasasti Sangsit $A$ atau Blantih $A$ yang berangka tahun 980 Saka atau 1058 Masehi yang terbit pada masa pemerintahan Raja Anak Wungsu terdapat ungkapan sebagai berikut: VIla.

...brahma VIlb. na ksatriya wesya sudra, hadyan hulun matuha, raray, lakilaki, wadwan, grahasta, wiku,...(Ardika dan Sutjiati Beratha, 1998: 203; Ardika dan Setiawan, 2012: 92).

Terjemahannya sebagai berikut:

brahmana, ksatriya, wesya, sudra, majikan, hamba, anakanak, laki-laki, perempuan, orang yang telah berumah tangga, dan bhiksu,...(Ardika dan Beratha, 1998: 203.

Sapatha atau kutukan merepresentasikan relasi kuasa dan pengetahuan raja-raja Bali Kuno tentang hukum dan ketentuanketentuan dalam agama Hindu. Ketentuan yang tersurat dalam sapatha merupakan acuan hukum dan pendisiplinan untuk masyarakat Bali Kuno. Masyarakat dari semua golongan, status dan umur yang berbeda diharapkan tidak melanggar ketentuan atau aturan yang telah ditetapkan oleh raja/penguasa. Sapatha dan ketentuan hukum yang belaku dapat dikatakan sebagai media pembelajaran dan pendisiplinan untuk seluruh masyarakat pada masa Bali Kuno. 


\section{KESIMPULAN}

Prasasti dan sapatha dapat dimaknai sebagai wacana yang diproduksi oleh raja-raja pada masa Bali Kuno untuk mengukuhkan dan menegakkan perintah dan kekuasaannya. Terdapat relasi kuasa dan pengetahuan yang tersurat dalam prasasti dan sapatha. Prasasti dan sapatha yang terbit pada periode yang lebih muda isinya lebih panjang dan lengkap (komprehensif) dibandingkan dengan yang tua. Dengan kata lain, pemahaman raja/penguasa tentang hukum Hindu selanjutnya dituliskan dalam prasasti guna memperkuat dan mengukuhkan kekuasaanya. Sapatha sebagai sanski moral dapat dimaknai sebagai media pendidikan, pendisiplinan dan alat kontrol oleh raja/penguasa pada masa Bali Kuno. Raja- raja/penguasa Bali Kuno melalui bahasa (soft power) yang dalam hal ini berupa prasasti dan sapatha menegaskan, mengukuhkan, mengatur, mengikat dan mengontrol semua golongan dalam masyarakat berdasarkan atas perbedaan status dan umur.

\section{UCAPAN TERIMA KASIH}

Terima kasih disampaikan kepada Ketua Lembaga Penelitian dan Pengabdian Masyarakat Universitas Udayana atas kepercayaan dan pendanaan yang diberikan pada tahun 2017 untuk melaksanakan penelitian ini. Kepada seluruh anggota Tim peneliti juga disampaikan terima kasih atas kerjasama dan koordinasinya yang baik selama penelitian ini. 


\section{DAFTAR PUSTAKA}

Althuser, Louis. 2008. Tentang Ideologi: Marxisme Strukturalis, Psikoanalisis, Cultural Studies. Yogyakarta: Jalasutra.

Ardika, I Wayan. 1991. Archaeological Research in Northeastern Bali, Indonesia. Unpublish Disertation.Canberra: Auatralian National University.

Ardika, I Wayan. 2013. 'Relasi Kuasa dan Penerapan Hukum Hindu pada Masa Bali Kuno'. Makalah ini disampaikan pada Seminar Nasional Sekolah Tinggi Agama Hindu Negeri Gde Pudja, Mataram, tanggal 13-15 September 2013.

Ardika, I Wayan dan N.L.Sutjiati Beratha. 1996. Perajin pada Masa Bali Kuno. Laporan Penelitian. Denpasar: Fakultas Sastra Universitas Udayana.

Ardika, I Wayan dan N.L.Sutjiati Beratha. 1998. Perajin pada Masa Bali Kuno. Laporan Penelitian. Denpasar: Fakultas Sastra Universitas Udayana.

Ardika, I Wayan dan I Ketut Setiawan, 2012. 'Bali antara Abad VIII-XIV: Upaya Rekonstruksi Sejarah Bali Kuno Berdasarkan Tinggalan Arkeologi'. Laporan Penelitian. Denpasar: Universitas Udayana.

Atmadja. 2016. Manusia sebagai Mahluk Multidimensional dalam Perspektif Komunikasi Lintas Budaya. Dalam Harmoni Sosial Lintas Budaya, 29-46. Editor oleh Ardika. Denpasar: Udayana University Press.

Barker, Chris. 2003. Kamus Kajian Budaya. Yogyakarta: PT Kanisius.

Bosch, F.D.K. ‘De oorkonde van Kembang Aroem'. OV, Bijlage B: 41-45.

Brandes, J.L.A. 1913. Oud-Javaansche Oorkonden, 128-134.

Callenfels, van Stein. 1926. Epigraphia Balica I, VBG, Deel LVI.6, Koleff \& Co.

Casparis, J.G.de. 1956. Prasasti Indonesia II. Bandung: Masa Baru.

Foucault, M. 2002. Power/Knowledge. Wacana Kuasa/Pengetahuan. Jogyakarta: Bentang Budaya.

Foucault. M. 1977. Translator. Alan Sheridan. Discipline and Punish. file://C:/Users/Vaio/Desktop/Documents/Discipline\%20and\%20Punish\%20 \%20Wikipedia.htm. Diunduh 25 Januari 2017

Goris, R. 1954. Prasasti Bali I \& II. Bandung: Masa Baru.

Hoed, Benny, H. 2008. Semiotika dan Dinamika Sosial Budaya. Depok: Fakultas Ilmu Budaya, Universitas Indonesia. 
Kartodirdjo, Sartono dkk. 1972. Sejarah Nasional Indonesia II. Jakarta: Balai Pustaka.

Lubis, Akhyar Yusuf. 2014. Teori dan Metodologi Ilmu Pengetahuan Sosial Budaya Kontemporer. Jakarta: PT Raja Grafindo Persada.

Lubis, Akhyar Yusuf. 2015. Pemikiran Kritis Kontemporer. Dari Teori Kritis, Culture Studies, Feminisme, Postkolonial hingga Multikulturalisme. Jakarta: PT RajaGrafindo Persada.

Santosa, Ida Bagus. 1965. Prasasti-prasasti Raja Anak Wungsu di Bali. Skripsi. Fakultas Sastra, Universitas Udayana.

Schrieke, B.J.O. 1919. Uit de Geschiedenisvan het Adatgrondenrecht, TBG. LIX: 122-190.

Schrieke, B.J.O. 1975. Sedikit Uraian Tentang Pranata Perdikan. Jakarta: Bhratara.

Setiawan, I Ketut dan I Wayan Ardika. 2013. 'Transliterasi dan Terjemahan Prasasti-Prasasti Bali Kuno Abad XII-XIV: Upaya Menggali Nilai-Nilai Kearifan Lokal untuk Memperkuat Jati Diri'. Laporan Penelitian. Denpasar: Universitas Udayana.

Suhadi, Machi, 1979. Himpunan Prasasti Bali. Koleksi R. Goris dan Ktut Ginarsa. Jakarta.

Takwin, Bagus. 2003. Akar-akar Ideologi. Yogyakarta: Jalasutra.

Thompson, John B. 2007. Analisis Ideologi, Kritik Wacana Ideologi-Ideologi Dunia Penerjemah. Haqqul Yaqin. Yogyakarta: IRCiSoD.

Vollenhoven, C. van 1931. Het Adatrecht van Nederlandsh Indie, Tweede deel, Leiden: Boekhandel en Drukkerij Voorheen E,J. Brill.

Wiguna, Tara IGN. 1981. Prasasti Bedulu suatu Kajian Epigrafis. Skripsi. Jakarta: Universitas Indonesia.

Zoetmulder, P.J. S.O Robson 1982. Old Javanese-English Dictionary I \& II. 'SGravenhage- Martinus Nijhoff: KITLV. 